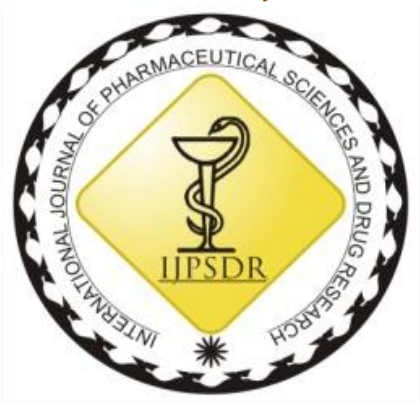

ISSN: 0975-248X

Research Article CODEN (USA): IJPSPP

(cc) BY-NC-SA

\title{
Design and in vivo Evaluation of Controlled Release Gliclazide Trilayer Matrix Tablets in the Management of Diabetes Mellitus
}

\author{
B. Ram Prasad, D.V.R.N. Bhikshapathi* \\ Mewar University, NH-79, Gangrar, Chhitorgarh-312901, Rajasthan, India
}

Copyright (C) 2018 B. Ram Prasad et al. This is an open access article distributed under the terms of the Creative Commons AttributionNonCommercial-ShareAlike 4.0 International License which allows others to remix, tweak, and build upon the work non-commercially, as long as the author is credited and the new creations are licensed under the identical terms.

\begin{abstract}
The purpose of the present study was to develop and optimize multi-layered matrix tablets of Gliclazide trilayer tablets to achieve zero-order drug release for sustained plasma concentration. Gliclazide tablets were prepared by direct compression and consist of middle active layer with different grades of hydroxypropyl methylcellulose (HPMC K 4M, K 15M and K100M), Guar gum and Eudragit L 100. The tablets were also evaluated for physicochemical characteristics and release kinetics. The physicochemical characteristics of the prepared tablets were satisfactory. The developed drug delivery systems showed prolonged drug release rates over a period of $24 \mathrm{~h}$. In vivo bioavailability studies were carried out on the optimized formulation (EF14), mean time to attain peak drug concentration $\left(\mathrm{T}_{\max }\right)$ was $6.00 \pm 0.14$ and $4.02 \pm 0.12 \mathrm{~h}$ for the optimized and marketed product respectively, while mean maximum drug concentration $\left(C_{\max }\right)$ was $124.80 \pm 1.02 \mathrm{ng} / \mathrm{ml}$ and $95.12 \pm 1.05 \mathrm{ng} / \mathrm{ml}$ respectively. $\mathrm{AUC}_{0-\alpha}$ and $\mathrm{AUC}_{0-\mathrm{t}}$ for optimized formulation was significantly higher $(p<0.05)$ as compared to marketed product. A fair correlation between the dissolution profile and bioavailability for the optimized formulation was observed. The results indicate that the approach used could lead to a successful development of a controlled release formulation of the drug. The EF14 was shown significant plasma concentration with controlled release and maintained for 24 hours with patient compliance by reducing the dosage frequency, when compared with marketed product in the efficient management of Diabetes mellitus.
\end{abstract}

Keywords: Gliclazide, Trilayer matrix tablet, HPMC, Guar gum, Pharmacokinetic studies.

*Corresponding author: Dr. D.V. R. N. Bhikshapathi

Address: Mewar University, NH-79, Gangrar, Chhitorgarh-312901, Rajasthan, India

Tel.: +91-9848514228

E-mail $\bowtie$ : dbpathi71@gmail.com

Relevant conflicts of interest/financial disclosures: The authors declare that the research was conducted in the absence of any commercial or financial relationships that could be construed as a potential conflict of interest.

Received: 31 July, 2018; Revised: 20 August, 2018; Accepted: 24 August, 2018; Published: 23 September, 2018

\section{INTRODUCTION}

Controlled release pharmaceutical systems have been developed and studied to improve the performance of drugs and to increase their pharmacological effect and reduce any side effect. [1] Several design options are available to control or modulate drug release from a drug delivery system. Most oral controlled release dosage forms fall in the category of matrix, reservoir or multi-layer systems. Lately, multi-layer matrix systems are gaining importance in the design of oral sustained drug delivery systems. A multi-layer system consists, usually, of a hydrophilic matrix core containing the 
active ingredient and one or two impermeable or semipermeable polymeric coatings (barrier-layer) applied on one or both faces of the core during tableting. [2] The barrier layers delay the interaction of active solute with dissolution medium, by limiting the surface available for the solute release and at the same time controlling solvent penetration rate. [3] In the device, the coat layers prevent the water penetration through the protected core for some duration. After this phase during the subsequent dissolution process, the swollen barriers erode and the surface available for drug release slowly increases. In this way the decrease of delivery rate due to the increase in diffusion path length is counter balanced by the simultaneous increase of the area available for drug release. [4]

Hydrophilic polymers have been given considerable attention in the formulation of controlled release drug delivery systems for various drugs. HPC, HPMC and Sodium CMC \& Carbopol are a few representative examples of the hydrophilic polymers that have been extensively used in the formulation of controlled release systems. [5] Guar gum is soluble in water; it swells in gastric fluid to produce a highly viscous layer around the tablet through which the drug can slowly diffuse and is used for the fabrication of matrices with uniform drug release characteristics. [6]

There have been different approaches to achieve zeroorder drug release from dosage forms for sustained plasma concentration. Among different approaches to achieve zero-order release from hydrophilic matrix technologies, multilayer matrices have been widely evaluated and developed for commercial products under the trade name of Geomatrix. The technology makes use of bilayer or trilayer tablets to modulate the release and to achieve constant release. [7]

Gliclazide is an oral hypo glycaemic second-generation sulfonyl urea drug which is useful for a long-term treatment of non-insulin dependent diabetes mellitus (NIDDM). Previous studies showed that gliclazide possesses good general tolerability, low incidence of hypo glycaemia and low rate of secondary failure. Rapid absorption from the GIT is required for the oral hypoglycaemic drug for effective therapy. However, the absorption rate of Gliclazide from the GIT is slow and varied among the subjects. Slow absorption has been suggested to be due to either poor dissolution of Gliclazide due to hydrophobic nature of drug and poor permeability of drug across the GI membrane. [8-9] By incorporation of Gliclazide in the trilayer tablet may control its absorption from GI tract and overcome the variability problems. Thus, this study was undertaken to develop controlled release trilayer matrix tablets of Gliclazide using release retardant and HPMC polymers up to $24 \mathrm{~h}$.

\section{MATERIALS AND METHODS}

\section{Materials}

Gliclazide (80 mg) film coated tablets were purchased from Orion Pharma Ltd, Mumbai. Gliclazide pure drug was generous gift from Aurobindo Pharma Limited, Hyderabad, India. Sodium carboxyl methyl cellulose, HPMC K 4 M, HPMC K 15 M \& HPMC K 100 M were obtained from Rubicon labs, Mumbai. Kondagogu gum, Eudragit L 100 and Carnauba wax were gifted from MSN Labs Ltd. Hyderabad. All other chemicals used were of analytical grade.

\section{Methods}

The following Pre-compression parameters were conducted: Angle of Repose [10], Carr's compressibility Index [11], Bulk Dentistry, Tapped Density [12], Hausner's Ratio. [13]

Formulation of controlled release Gliclazide trilayer matrix tablets

The trilayered matrix tablets of Gliclazide were prepared by direct compression method. The first step in the formulation was to develop the middle active layer so as to give at least $90 \%$ drug release during 12 hours. The release profile of this layer might not be of constant rate type but would be preferably of constantly falling rate type. This layer would then be sandwiched between barrier layers (Upper \& Lower layers) so as to continue the drug release for $24 \mathrm{~h}$.

Preparation of middle active layer

Sixteen formulations (F1-F16) for active layer were prepared by direct compression method using polymers like different HPMC grades, Kondagogu gum, Sodium CMC, DCP. All the formulations were varied in concentration of polymers, talc $(1.5 \mathrm{mg})$ \& magnesium stearate $(1.5 \mathrm{mg})$ constituted in all the formulations. These materials were screened through $\neq 60$ and mixed together in motor by using pestle. Final mixtures were compressed by using $12 \mathrm{~mm}$ diameter flat punches on a sixteen-station rotary tablet press. Formulation of active layer was depicted in table 1, 2. The prepared tablets were subjected to dissolution studies.

\section{Preparation of upper and lower layers}

The barrier layers were formulated employing hydrophobic swellable polymer natural wax i.e. carnauba wax the swelling erosion modelling fillers which include water soluble DCP, EC and Kondagogu gum. The procedure tried to make the compacts was via direct compressions. For the first procedure the wax, Kondagogu gum and the filler was mixed in motor and lubricated with magnesium stearate. Formulation of upper and lower layers was depicted.

\section{Formulation of Gliclazide trilayer tablets}

The powder mixtures required for active and barrier layers were weighed accurately and thoroughly mixed using mortar and pestle for about 20 minutes. Initially, the volume of die cavity (12 $\mathrm{mm}$, round) was adjusted equivalence to the weight of trilayered matrix tablets (500 mg). Then the pre-weighed amount of powder equivalent to bottom layer (125 $\mathrm{mg}$ ) was taken and placed in the die cavity and slightly compressed for uniform spreading. The upper punch was lifted up and $250 \mathrm{mg}$ of the drug containing middle active layer optimized formulation (F14) was placed over the 
bottom layer in the die cavity and again slightly compressed. The remaining volume of the die cavity was filled with pre-weighed (125 mg) amount of powder equivalent to top layer and compressed with the full force of compression on rotary tablets press to obtain tri-layered tablets. Tri-layered matrix tablets of each composition were compressed and tested for their friability, Hardness, drug content and drug release characteristics with a suitable number of tablets for each test.

Evaluation tests of trilayer matrix tablets performed by Hardness, Friability [14], Weight variation, Drug content / Assay [15], Swelling \& Erosion studies. [16]

In-vitro drug release profile

In vitro drug release studies for developed trilayer matrix tablets were carried out by using dissolution apparatus II paddle type (Electrolab TDL-08L). The drug release profile was studied in $900 \mathrm{ml}$ Phosphate buffer $\mathrm{pH} 7.2$ at $37 \pm 0.5^{\circ} \mathrm{C}$ temperature. The amount of drug release was determined by UV visible spectrophotometer (Shimadzu UV 1800) at $229 \mathrm{~nm}$.

\section{Drug-excipient compatibility studies}

Fourier Transform Infrared Spectroscopy (FTIR) and Differential Scanning Calorimetry (DSC) ${ }^{[17]}$

\section{Stability studies}

The stability study of the formulated trilayer tablets were carried out under different conditions according to ICH guidelines using stability chamber (REMI make). Accelerated Stability studies were carried out at $40^{\circ} \mathrm{C} / 75 \% \mathrm{RH}$ for the best formulations for 6 months. The tablets were characterized for the hardness, friability, drug content and cumulative \% drug release during the stability study period.

Pharmacokinetic study

Animal Preparation
Male rabbits were (weighing 2-3 $\mathrm{Kg}$ ) selected for this study, all the animals were healthy during the period of the experiment. Animals were maintained at room temperature $25^{\circ} \mathrm{C}$, Relative Humidity $45 \%$ and $12 \mathrm{~h}$ alternate light and dark cycle with $100 \%$ fresh air exchange in animal rooms, uninterrupted power and water supply and rabbits were fed with standard diet and water ad libitum. The protocol of animal study was approved by the institutional animal ethics committee (IAEC NO: IAEC NO: P44/VCP/IAEC/2015/10/DBP/ AE12/Rabbits).

In vivo study design

The Rabbits were randomly divided into two groups each group contains six animals. The group A was received prepared Gliclazide matrix Tablets $(80 \mathrm{mg})$, marketed product $(80 \mathrm{mg})$ was administered group B with equivalent dose of animal body weight. Blood samples (approximately $0.5 \mathrm{ml}$ ) were obtained with syringes by marginal ear vein at $0,1,2,4,6,8,12,16,20$ and 24 hours post dose. During collection, blood sample has been mixed thoroughly with heparin in order to prevent blood clotting. Plasma was separated by centrifugation of the blood at $5000 \mathrm{rpm}$ in cooling centrifuge for $5 \mathrm{~min}$ to 10 minutes and stored frozen at $-20^{\circ} \mathrm{C}$ until analysis.

\section{HPLC method}

For HPLC C8 column with $5 \mu \mathrm{m}$ particle size and the mobile phase consisted of acetonitrile and water $(\mathrm{pH}=$ $2.5 \pm 0.2$ adjusted with phosphoric acid) $(55: 45 \mathrm{v} / \mathrm{v})$, and delivered at a flow rate of $1 \mathrm{ml} / \mathrm{min}$. The eluted peaks were detected by a UV detector was set at wavelength of $230 \mathrm{~nm} \mathrm{~nm}$. Internal standard glipizide was used. The retention times of gliclazide and glipizide (IS) were around 6.1 and 3.8 respectively. [18]

Table 1: Formulation trails for middle active layer

\begin{tabular}{|c|c|c|c|c|c|c|c|c|c|c|c|c|c|c|c|c|}
\hline Ingredients (mg) & F1 & F2 & F3 & $\mathbf{F 4}$ & F5 & F6 & F7 & F8 & F9 & F10 & F11 & F12 & F13 & F14 & F15 & F16 \\
\hline Gliclazide & 80 & 80 & 80 & 80 & 80 & 80 & 80 & 80 & 80 & 80 & 80 & 80 & 80 & 80 & 80 & 80 \\
\hline HРMC К 4M & 60 & 65 & 70 & --- & --- & ---- & ---- & ---- & ---- & 30 & 35 & 35 & ---- & ---- & ---- & ---- \\
\hline HPMC K 15M & --- & --- & ---- & 60 & 65 & 70 & --- & ---- & ---- & 30 & 30 & 35 & ---- & ---- & ---- & --- \\
\hline НРМС К 100M & --- & --- & --- & ---- & --- & ---- & 60 & 65 & 70 & ----- & ---- & ---- & 60 & 65 & 70 & 75 \\
\hline Eudragit L 100 & 32 & 40 & 42 & 32 & 40 & 42 & 32 & 40 & 42 & 32 & 40 & 42 & 32 & 40 & 42 & 42 \\
\hline Guar gum & 20 & 22 & 25 & 20 & 22 & 25 & 20 & 22 & 25 & 20 & 22 & 25 & 20 & 22 & 25 & 25 \\
\hline $\begin{array}{l}\text { Sodium carboxy methyl } \\
\text { cellulose }\end{array}$ & 25 & 15 & 10 & 25 & 15 & 10 & 25 & 15 & 10 & 25 & 15 & 10 & 25 & 15 & 10 & 15 \\
\hline Dibasic calcium phosphate & 30 & 25 & 20 & 30 & 25 & 20 & 30 & 25 & 20 & 30 & 25 & 20 & 30 & 25 & 20 & 20 \\
\hline
\end{tabular}

Table 2: Composition of Gliclazide trilayer matrix tablet

\begin{tabular}{|c|c|c|c|c|c|c|c|c|}
\hline Ingredients & AF14 & BF14 & CF14 & DF14 & EF14 & FF14 & GF14 & HF14 \\
\hline \multicolumn{9}{|c|}{ Middile Active Layer (F14) (mg) } \\
\hline Gliclazide & 80 & 80 & 80 & 80 & 80 & 80 & 80 & 80 \\
\hline HРMC K 100M & 65 & 65 & 65 & 65 & 65 & 65 & 65 & 65 \\
\hline Eudragit L 100 & 40 & 40 & 40 & 40 & 40 & 40 & 40 & 40 \\
\hline Guar gum & 22 & 22 & 22 & 22 & 22 & 22 & 22 & 22 \\
\hline Sodium carboxy methyl cellulose & 15 & 15 & 15 & 15 & 15 & 15 & 15 & 15 \\
\hline Dibasic calcium phosphate & 25 & 25 & 25 & 25 & 25 & 25 & 25 & 25 \\
\hline \multicolumn{9}{|c|}{ Upper And Lower Layer (mg) } \\
\hline Carnauba wax & 20 & 25 & 30 & 35 & 40 & 42.5 & 45 & 50 \\
\hline Ethyl cellulose & 52 & 50 & 52 & 47 & 50 & 42.5 & 42 & 42 \\
\hline Dibasic calcium phosphate & 50 & 47 & 40 & 40 & 32 & 35 & 35 & 30 \\
\hline Magnesium stearate & 1.5 & 1.5 & 1.5 & 1.5 & 1.5 & 1.5 & 1.5 & 1.5 \\
\hline Talc & 1.5 & 1.5 & 1.5 & 1.5 & 1.5 & 1.5 & 1.5 & 1.5 \\
\hline
\end{tabular}


Preparation of Plasma Samples for HPLC Analysis

Rabbit plasma $(0.5 \mathrm{ml})$ samples were prepared for chromatography by precipitating proteins with $2.5 \mathrm{ml}$ of ice-cold absolute ethanol for each $0.5 \mathrm{ml}$ of plasma. After centrifugation the ethanol was transferred into a clean tube. The precipitate was re suspended with $1 \mathrm{ml}$ of Acetonitrile by vortexing for $1 \mathrm{~min}$. After centrifugation (5000-6000 $\mathrm{rpm}$ for $10 \mathrm{~min})$, the Acetonitrile was added to the ethanol and the organic mixture was taken to near dryness by a steam of nitrogen at room temperature.

Pharmacokinetic analysis

The pharmacokinetic parameters employed to evaluate were maximum plasma concentration $\left(\mathrm{C}_{\max }\right)$, time to attain $C_{\max }$ i.e., $T_{\max }$ and $t_{1 / 2}$ values, area under plasma concentration-time curve from zero to the last sampling time $\left(\mathrm{AUC}_{0-\mathrm{t}}\right)$, area under plasma concentration-time curve from zero to infinity $\left(\mathrm{AUC}_{0}\right.$ $\left.{ }_{\infty}\right)$. $\mathrm{AUC}_{0-\mathrm{t}}$ was calculated by the linear trapezoidal rule and $\mathrm{AUC}_{0-\infty}$ from the following formula.

$$
\mathrm{AUC}_{0-\infty}=\mathrm{AUC}_{0-\mathrm{t}}+\mathrm{C}_{\mathrm{t}} / \mathrm{K}_{\mathrm{E}}
$$

\section{RESULTS AND DISCUSSION}

\section{Pre-compression parameters}

All the powder mixture belonging to different formulations was tested for micrometrics studies in order to determine the flow properties. All the formulations AF14 to HF14 showed good flow properties, the results are summarized in table 3.

\section{TRILAYER TABLETS}

\section{Preparation of middle active layer}

The matrix tablets of Gliclazide were prepared without the barrier layers. All the formulation trails were subjected to in vitro dissolution to determine the release profiles. From the above results, among all the Table 4: Dissolution profile of different formulations Gliclazide active layer (F1-F8)

\begin{tabular}{|c|c|c|c|c|c|c|c|c|}
\hline Time (h) & F1 & F2 & F3 & F4 & F5 & F6 & F7 & F8 \\
\hline 0 & 0 & 0 & 0 & 0 & 0 & 0 & 0 & 0 \\
\hline 1 & $15.18 \pm 0.95$ & $18.19 \pm 0.98$ & $17.24 \pm 0.97$ & $22.34 \pm 1.05$ & $19.03 \pm 0.99$ & $13.26 \pm 0.93$ & $16.14 \pm 0.96$ & $21.68 \pm 1.02$ \\
\hline 2 & $32.20 \pm 2.23$ & $35.36 \pm 2.24$ & $21.36 \pm 1.30$ & $33.67 \pm 2.20$ & $28.56 \pm 1.36$ & $25.64 \pm 1.38$ & $24.38 \pm 1.36$ & $30.13 \pm 2.01$ \\
\hline 4 & $40.38 \pm 2.45$ & $46.14 \pm 2.65$ & $30.18 \pm 2.01$ & $38.14 \pm 2.19$ & $37.28 \pm 2.34$ & $34.67 \pm 2.12$ & $32.47 \pm 2.10$ & $48.24 \pm 2.69$ \\
\hline 6 & $52.64 \pm 2.85$ & $59.58 \pm 2.96$ & $48.27 \pm 2.69$ & $45.23 \pm 2.62$ & $50.12 \pm 2.80$ & $48.67 \pm 2.68$ & $47.56 \pm 2.66$ & $59.75 \pm 2.96$ \\
\hline 8 & $64.38 \pm 3.15$ & $69.32 \pm 3.32$ & $59.46 \pm 2.96$ & $64.12 \pm 3.18$ & $68.14 \pm 3.32$ & $62.17 \pm 3.10$ & $57.52 \pm 2.99$ & $60.36 \pm 2.97$ \\
\hline 10 & $77.29 \pm 3.84$ & $72.08 \pm 3.80$ & $75.04 \pm 3.88$ & $82.78 \pm 4.51$ & $89.24 \pm 4.98$ & $74.16 \pm 3.88$ & $76.61 \pm 3.83$ & $78.41 \pm 3.95$ \\
\hline 12 & $89.44 \pm 4.99$ & $93.14 \pm 5.03$ & $91.21 \pm 5.01$ & $93.54 \pm 5.10$ & $95.12 \pm 5.15$ & $88.17 \pm 4.89$ & $92.32 \pm 5.08$ & $90.32 \pm 5.01$ \\
\hline
\end{tabular}

Table 5: Dissolution profile of different formulations Gliclazide active layer (F9-F16)

\begin{tabular}{|c|c|c|c|c|c|c|c|c|}
\hline Time (h) & F9 & F10 & F11 & F12 & F13 & F14 & F15 & F16 \\
\hline 0 & 0 & 0 & 0 & 0 & 0 & 0 & 0 & 0 \\
\hline 1 & $14.20 \pm 0.94$ & $18.04 \pm 0.98$ & $20.78 \pm 1.01$ & $16.04 \pm 0.96$ & $19.24 \pm 0.99$ & $29.09 \pm 1.40$ & $17.29 \pm 0.97$ & $22.54 \pm 1.08$ \\
\hline 2 & $25.34 \pm 1.37$ & $29.56 \pm 1.97$ & $28.57 \pm 1.97$ & $28.56 \pm 1.58$ & $22.38 \pm 1.33$ & $47.78 \pm 2.79$ & $26.30 \pm 1.36$ & $35.21 \pm 2.15$ \\
\hline 4 & $38.30 \pm 2.42$ & $38.17 \pm 2.40$ & $37.64 \pm 2.40$ & $30.89 \pm 2.50$ & $36.19 \pm 2.15$ & $58.12 \pm 2.96$ & $35.48 \pm 2.15$ & $50.17 \pm 2.81$ \\
\hline 6 & $46.38 \pm 2.67$ & $54.84 \pm 2.70$ & $50.32 \pm 2.60$ & $42.38 \pm 2.60$ & $58.27 \pm 2.85$ & $67.36 \pm 3.78$ & $58.51 \pm 2.95$ & $62.38 \pm 3.12$ \\
\hline 8 & $69.74 \pm 3.26$ & $68.39 \pm 3.25$ & $60.19 \pm 3.10$ & $62.17 \pm 3.83$ & $74.54 \pm 3.78$ & $79.48 \pm 3.97$ & $75.27 \pm 3.81$ & $71.17 \pm 3.80$ \\
\hline 10 & $75.96 \pm 3.83$ & $80.47 \pm 4.32$ & $75.27 \pm 3.83$ & $74.58 \pm 3.51$ & $80.67 \pm 4.55$ & $88.57 \pm 4.98$ & $85.66 \pm 4.68$ & $84.23 \pm 4.62$ \\
\hline 12 & $89.30 \pm 4.99$ & $91.05 \pm 5.02$ & $93.28 \pm 5.10$ & $89.03 \pm 4.99$ & $90.24 \pm 5.01$ & $99.60 \pm 5.25$ & $92.30 \pm 5.02$ & $94.19 \pm 5.12$ \\
\hline
\end{tabular}

Table 6: Physical evaluation of Trilayer tablets

\begin{tabular}{|c|c|c|c|c|c|c|c|c|c|}
\hline S. No & Tests & AF14 & BF14 & CF14 & DF14 & EF14 & FF14 & GF14 & HF14 \\
\hline 1 & Hardness $\left(\mathrm{Kg} / \mathrm{Cm}^{2}\right)$ & $7.2 \pm 0.15$ & $6.1 \pm 0.10$ & $6.8 \pm 0.24$ & $7.1 \pm 0.10$ & $7.8 \pm 0.26$ & $7.5 \pm 0.18$ & $6.7 \pm 0.23$ & $7.3 \pm 0.16$ \\
\hline 2 & Friability (\%) & 0.15 & 0.28 & 0.26 & 0.30 & 0.35 & 0.18 & 0.23 & 0.24 \\
\hline 3 & Weigh variation (mg) & $596 \pm 20$ & $599 \pm 20$ & $595 \pm 20$ & $594 \pm 20$ & $597 \pm 20$ & $595 \pm 20$ & $596 \pm 20$ & $600 \pm 20$ \\
\hline 4 & Assay (\%) & 97.51 & 96.82 & 96.24 & 97.07 & 98.96 & 97.41 & 96.12 & 95.14 \\
\hline
\end{tabular}


Table 7 (a): In-vitro dissolution studies of Gliclazide Trilayer tablets

\begin{tabular}{cccccc}
\hline Time (h) & AF14 & BF14 & CF14 & DF14 & EF14 \\
\hline 0 & $0 \pm 0$ & $0 \pm 0$ & $0 \pm 0$ & $0 \pm 0$ & $12.24 \pm 0.54$ \\
1 & $5.26 \pm 0.35$ & $8.26 \pm 0.38$ & $10.47 \pm 0.48$ & $20.24 \pm 1.01$ & $15.26 \pm 0.95$ \\
2 & $18.29 \pm 0.98$ & $15.14 \pm 0.95$ & $13.36 \pm 0.93$ & $30.36 \pm 2.10$ & $37.14 \pm 2.18$ \\
4 & $22.46 \pm 1.08$ & $25.26 \pm 1.28$ & $28.39 \pm 1.30$ & $42.39 \pm 2.67$ & $46.39 \pm 2.69$ \\
6 & $34.67 \pm 2.15$ & $30.12 \pm 2.10$ & $32.64 \pm 2.10$ & $54.14 \pm 2.41$ & $58.64 \pm 2.45$ \\
8 & $48.29 \pm 2.70$ & $42.34 \pm 2.67$ & $45.63 \pm 2.68$ & $63.66 \pm 2.60$ & $67.39 \pm 2.70$ \\
10 & $54.67 \pm 2.41$ & $51.26 \pm 2.38$ & $58.47 \pm 2.45$ & $71.29 \pm 3.77$ & $77.66 \pm 3.85$ \\
12 & $65.23 \pm 2.63$ & $63.40 \pm 2.60$ & $60.24 \pm 2.58$ & $82.14 \pm 4.32$ & $89.24 \pm 4.98$ \\
16 & $74.28 \pm 3.81$ & $72.16 \pm 3.78$ & $76.29 \pm 3.84$ & $89.45 \pm 4.98$ & $92.14 \pm 5.04$ \\
20 & $82.19 \pm 4.34$ & $84.39 \pm 4.38$ & $80.15 \pm 4.30$ & $96.17 \pm 5.15$ & $98.26 \pm 5.39$ \\
24 & $92.14 \pm 5.01$ & $90.24 \pm 5.00$ & $94.39 \pm 5.10$ & &
\end{tabular}

Table 7 (b): In-vitro dissolution studies of Gliclazide Trilayer

\begin{tabular}{ccccc} 
tablets & & & & \\
\hline Time (h) & FF14 & GF14 & HF14 & COMPRID \\
\hline 0 & $0 \pm 0$ & $0 \pm 0$ & $0 \pm 0$ & $0 \pm 0$ \\
1 & $11.29 \pm 0.53$ & $13.18 \pm 0.93$ & $7.38 \pm 0.37$ & $3.16 \pm 0.30$ \\
2 & $14.14 \pm 0.94$ & $22.25 \pm 1.08$ & $24.15 \pm 1.27$ & $8.24 \pm 0.38$ \\
4 & $18.28 \pm 0.98$ & $33.18 \pm 2.14$ & $35.64 \pm 2.16$ & $15.26 \pm 0.95$ \\
6 & $25.16 \pm 1.28$ & $45.67 \pm 2.68$ & $40.19 \pm 2.65$ & $22.14 \pm 1.08$ \\
8 & $37.14 \pm 2.18$ & $56.34 \pm 2.45$ & $53.28 \pm 2.41$ & $30.18 \pm 2.10$ \\
10 & $48.67 \pm 2.70$ & $65.26 \pm 2.63$ & $60.28 \pm 2.58$ & $42.13 \pm 2.67$ \\
12 & $52.39 \pm 2.39$ & $74.26 \pm 3.81$ & $73.14 \pm 3.79$ & $48.29 \pm 2.70$ \\
16 & $68.17 \pm 2.71$ & $80.24 \pm 4.32$ & $85.16 \pm 4.85$ & $59.26 \pm 2.48$ \\
20 & $75.36 \pm 3.83$ & $85.36 \pm 4.38$ & $87.29 \pm 4.97$ & $70.16 \pm 3.75$ \\
24 & $89.28 \pm 4.98$ & $91.63 \pm 5.01$ & $93.64 \pm 5.05$ & $95.26 \pm 5.15$
\end{tabular}

Table 8: Pharmacokinetic Parameters of Gliclazide optimized formulation and marketed product

\begin{tabular}{ccc}
\hline Parameters & $\begin{array}{c}\text { Gliclazide Optimized } \\
\text { formulation }\end{array}$ & Marketed product \\
\hline $\mathrm{C}_{\max }(\mathrm{ng} / \mathrm{ml})$ & $124.80 \pm 1.02$ & $95.12 \pm 1.05$ \\
$\mathrm{AUC}_{0-\mathrm{t}}(\mathrm{ng} \mathrm{h} / \mathrm{ml})$ & $330.65 \pm 1.12$ & $212.25 \pm 1.02$ \\
$\mathrm{AUC}_{0-\infty}(\mathrm{ng} \mathrm{h} / \mathrm{ml})$ & $417.75 \pm 1.14$ & $328.14 \pm 1.02$ \\
$\mathrm{~T}_{\max }(\mathrm{h})$ & $6.00 \pm 0.14$ & $4.02 \pm 0.12$ \\
$\mathrm{t}_{1 / 2}(\mathrm{~h})$ & $7.5 \pm 0.014$ & $5.15 \pm 0.05$ \\
\hline
\end{tabular}

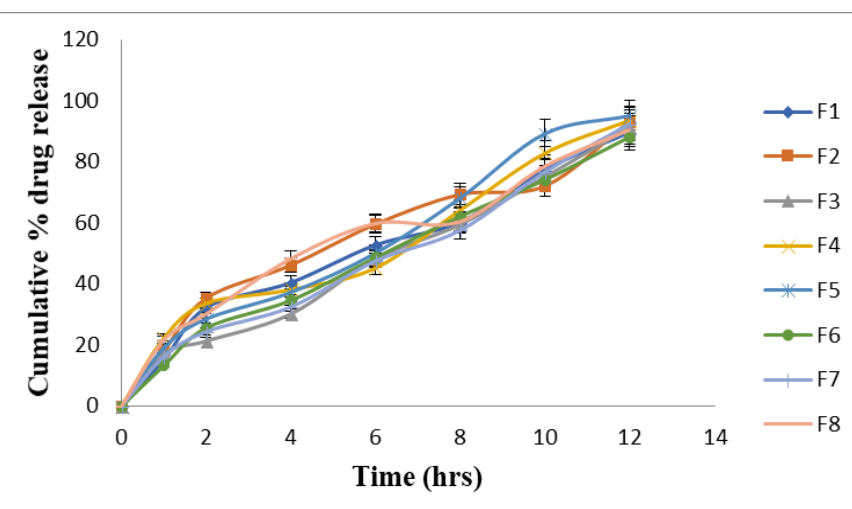

Fig. 1: In vitro Dissolution profile of F1-F8 Gliclazide active layer formulations

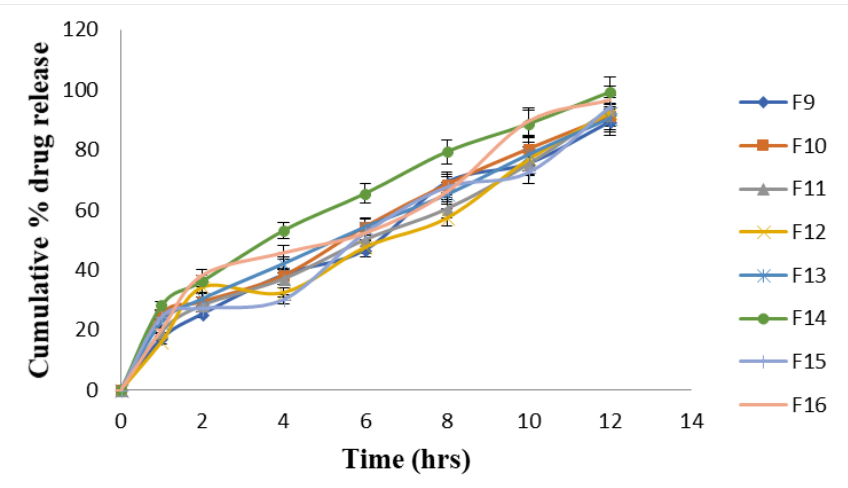

Fig. 2: In vitro Dissolution profile of F9-F16 Gliclazide active layer formulations

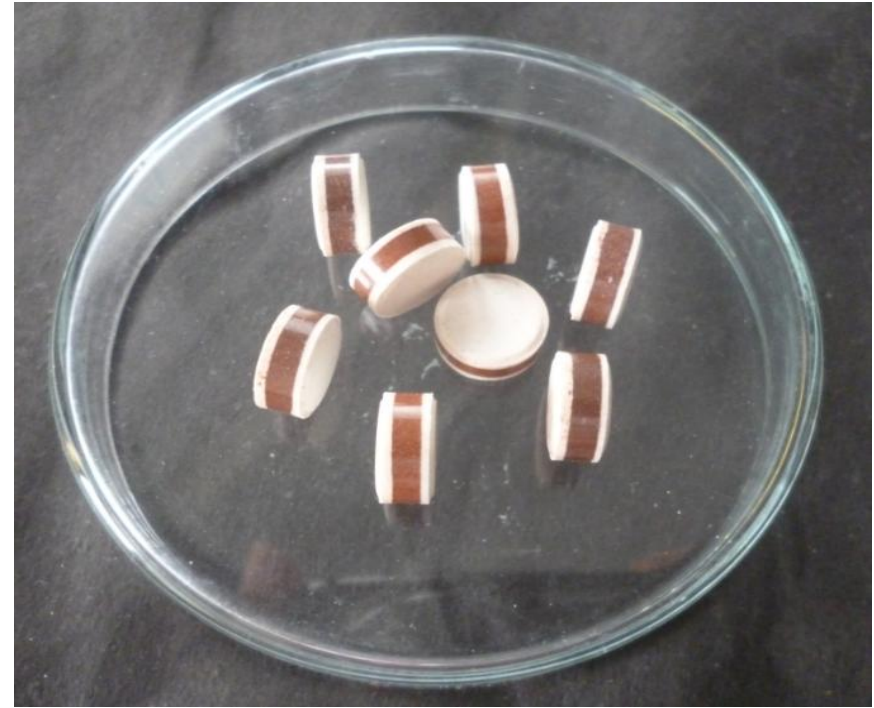

Fig. 3: Preparation of Gliclazide trilayer matrix tablets

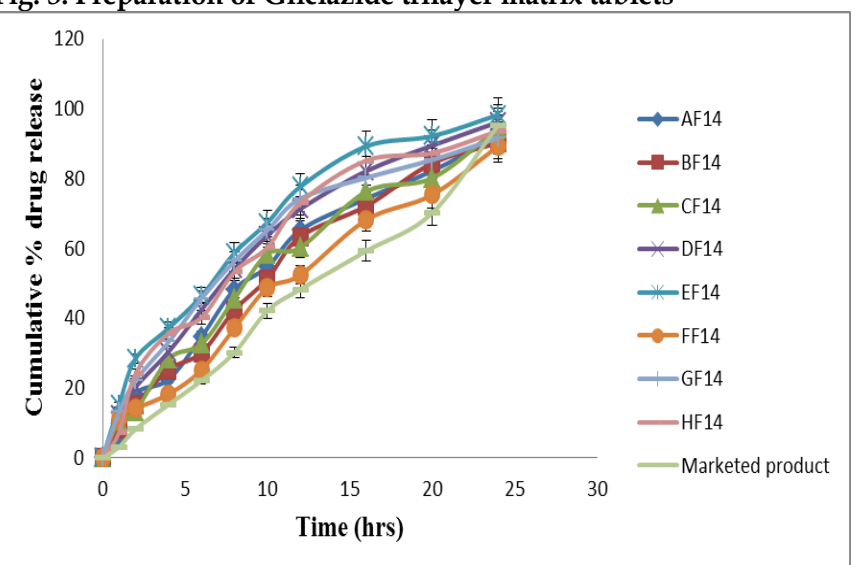

Fig. 4: In-vitro dissolution studies of AF14-HF14

In vitro dissolution studies of Gliclazide Trilayer tablets

The release of Gliclazide from different formulations was carried out in phosphate buffer $\mathrm{pH} 6.8$ and the results are depicted in Tables 7(a) and 7(b). The trilayer tablets extended the drug release up to 24 hours. The highest drug release was found in the formulation EF14 i.e $98.29 \%$ within $24 \mathrm{~h}$. EF14 was found to be optimized formulation based on the dissolution and other evaluation parameters. The comparison of marketed product Gliclazide $(200 \mathrm{mg})$ film coated tablet and optimized formulation EF14 was shown in figure 4. The drug release from marketed product was $95.26 \%$ within 24 hours. 


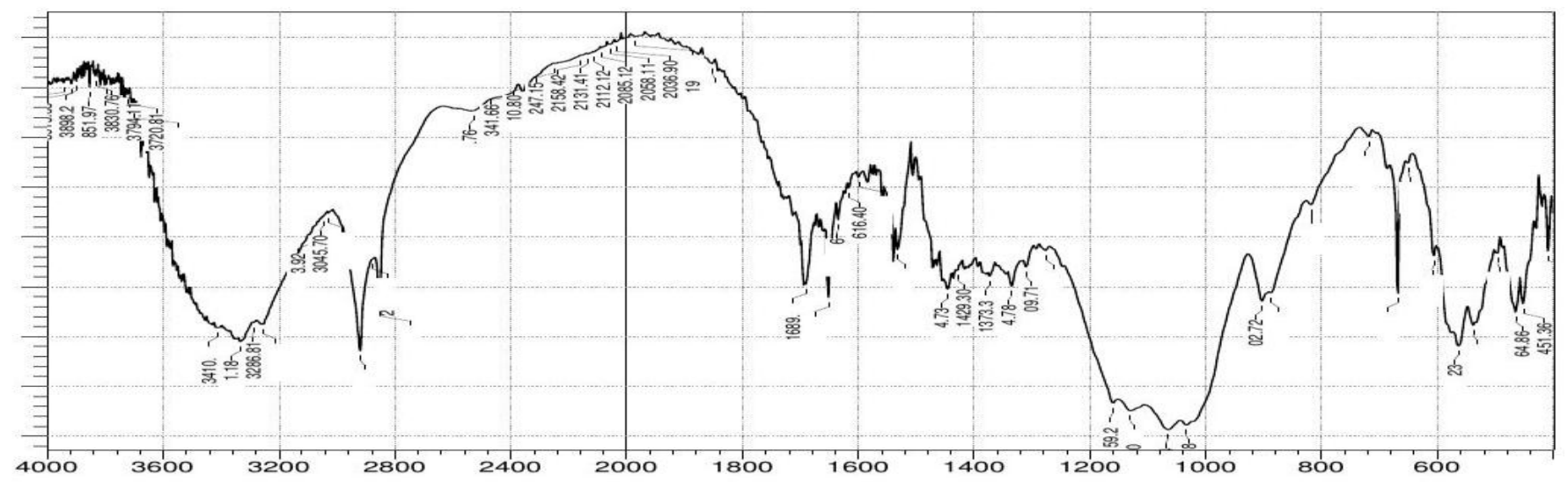

Fig. 7: FT-IR spectrum of pure drug Gliclazide

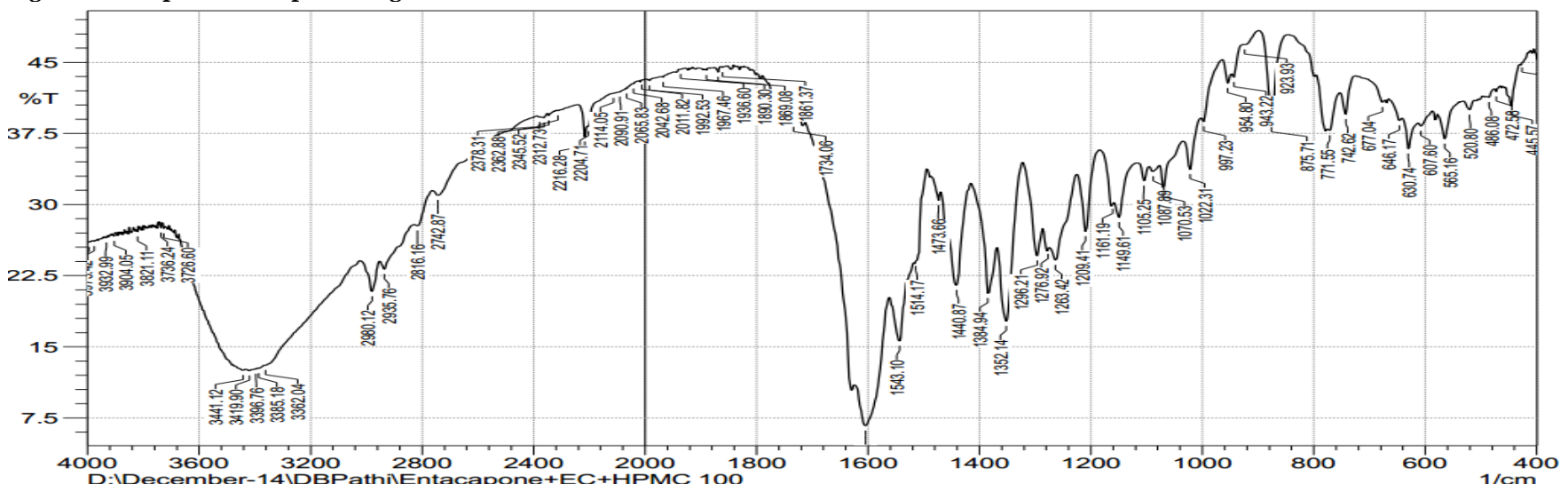

Fig. 8: FT-IR spectrum of pure drug and other polymers

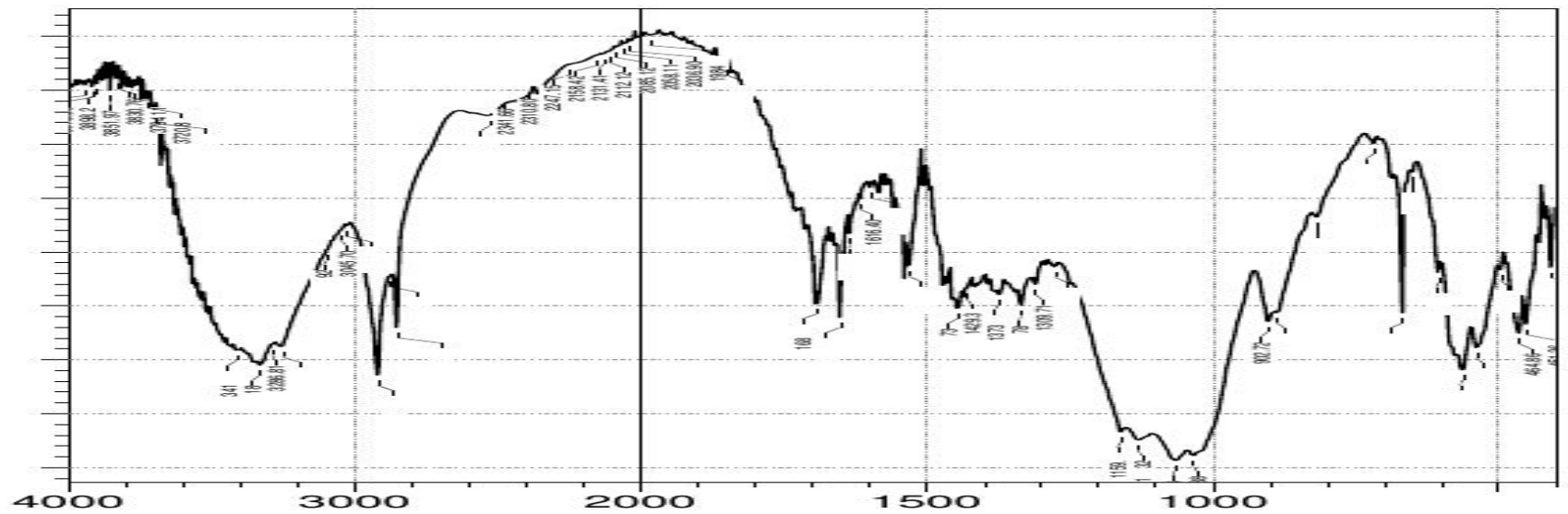

Fig. 9: FT-IR spectrum of optimized formulation EF14

In vitro dissolution studies of Gliclazide Trilayer tablets formulated in different trails

\section{Characterization}

FT-IR

Overall there was no alteration in peaks of Gliclazide pure drug (figure 7) and optimized formulation (figure 9), suggesting that there was no interaction between drug \& excipients. FT-IR spectrum of pure drug and other polymers are shown in (figure 8). There are additional peaks appeared or disappeared hence no significant changes in peaks of optimized formulation was observed when compared to pure drug indicating absence of any interaction.

DSC studies

DSC was used to detect interaction between Gliclazide and excipients. The thermogram of Gliclazide exhibited a sharp endotherm melting point at $163^{\circ} \mathrm{C}$. The thermo gram of optimized formulation of Gliclazide exhibited a sharp endotherm melting point at $165^{\circ} \mathrm{C}$. The DSC thermo gram retained properties of Gliclazide, as well as polymer properties. There is no considerable change observed in melting endotherm of drug in optimized formulation (figure 10). It indicates that there is no interaction between drug \& excipients used in the formulation.

\section{Stability studies}

Optimized formulation was selected for stability studies on the basis of high cumulative \% drug release. Stability studies were conducted for 6 months according to ICH guidelines. From these results it was concluded that, optimized formulation is stable and retained their original properties with minor differences. 


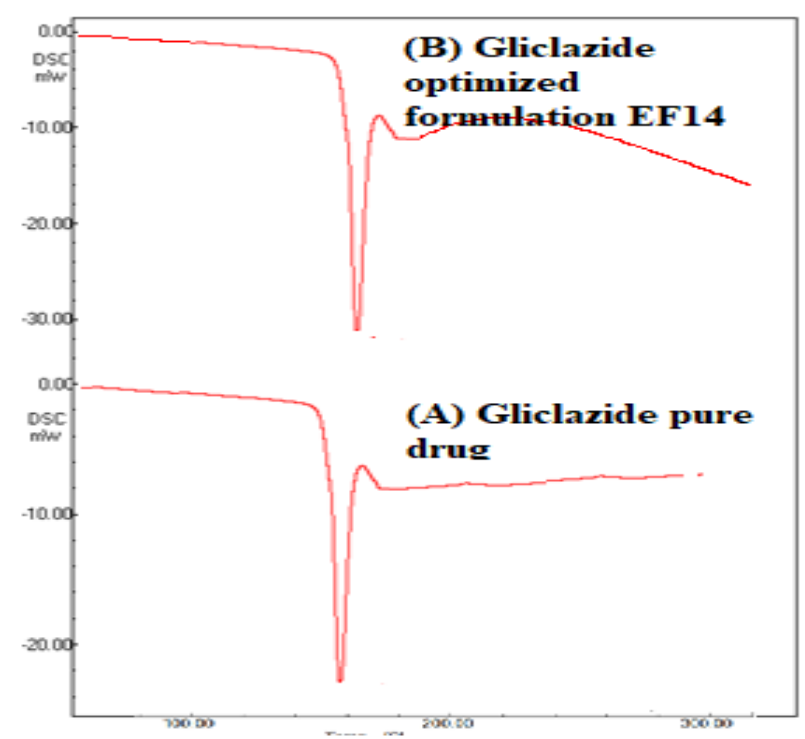

Fig. 10: DSC thermogram of Gliclazide pure drug (A) and optimized formulatin EF14 (B)

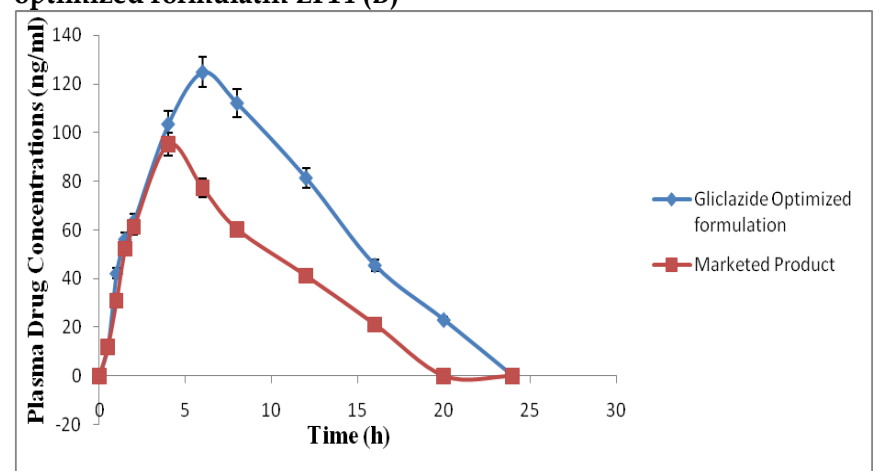

Fig. 11: Plasma concentrations of gliclazide Optimized formulation (EF14) and Marketed Product at different time intervals

\section{Bioavailability Parameters}

Mean plasma concentration profiles of prepared gliclazide optimized formulation and Marketed product are presented in figure 11. Gliclazide optimized formulation exhibited as sustained release in vivo when compared with Marketed product. All the pharmacokinetics parameters displayed in table 8 . The release pattern of both marketed and test formulation showing sustained release pattern. The $\mathrm{T}_{\max }$ of the optimized formulation was $(6.01 \pm 0.04 \mathrm{~h})$ and Marketed Product $\mathrm{T}_{\max }$ was $(4.02 \pm 0.12 \mathrm{~h})$. This delayed absorption of test and marketed preparations most likely due to the sustained release of the drugs. On the other hand, the $C_{\max }$ of reference formulation (95.12 \pm $1.05 \mathrm{ng} / \mathrm{ml}$ ) was significantly different from the test preparation $(124.80 \pm 1.02 \mathrm{ng} / \mathrm{ml})$. However, the $\mathrm{AUC}_{0}$ $\infty$ values for the two formulations were significantly different test formulation $(417.75 \pm 1.14 \mathrm{ng} \mathrm{h} / \mathrm{ml})$ and marketed $(328.14 \pm 1.02 \mathrm{ng} \mathrm{h} / \mathrm{ml})$. This suggests that the gliclazide contained in the test product was completely absorbed showing more bioavailability when compared with marketed Product.

It was concluded that Trilayer matrix tablets of Gliclazide can be successfully prepared by direct compression technique using different polymers combination. Based on the evaluation parameters, drug dissolution profile and release drug kinetics EF14 was found to be optimized formulation. In vitro studies were conducted for optimized Gliclazide trilayer tablets and marketed product, the results were indicating that the optimized Gliclazide formulation was shown sustained release patterns where marketed product was shown immediate release. In vivo bioavailability studies were carried out on the optimized formulation (EF14), mean time to attain peak drug concentration $\left(\mathrm{T}_{\max }\right)$ was $6.00 \pm 0.14$ and $4.02 \pm 0.12 \mathrm{~h}$ for the optimized and marketed product respectively, while mean maximum drug concentration $\left(\mathrm{C}_{\max }\right)$ was $124.80 \pm 1.02 \mathrm{ng} / \mathrm{ml}$ and $95.12 \pm 1.05 \mathrm{ng} / \mathrm{ml}$ respectively. $\mathrm{AUC}_{0-\mathrm{\alpha}}$ and $\mathrm{AUC}_{0-\mathrm{t}}$ for optimized formulation was significantly higher $(p<0.05)$ as compared to marketed product. A fair correlation between the dissolution profile and bioavailability for the optimized formulation was observed. The results indicate that the approach used could lead to a successful development of a controlled release formulation of the drug. The HF14 was shown significant plasma concentration with controlled release and maintained for 24 hours with patient compliance by reducing the dosage frequency, when compared with marketed product in the efficient management of Diabetes mellitus.

\section{REFERENCES}

1. Thirupathaiah A, Shyam SR. Preparation and In Vivo Evaluation of Extended Release Trilayer Matrix Tablets Containing Simvastatin Solid Dispersions. Am. J. PharmTech Res. 2016; 6(5).

2. Efentakis M, Politis S. Comparative evaluation of various structures in polymer-controlled drug delivery systems and the effect of their morphology and characteristics on drug release. Eur. Polym. J. 2006; 42:1183-1195.

3. Conte U, Maggi L, Colombo P, La MA. Multi-layered hydrophilic matrices as constant release devices. J Control Rel. 1993; 26: 39-47.

4. Conte U, Maggi L. Modulation from Geomatrix multi-layer matrix tablets containing drugs of different solubility. Biomaterials. 1996; 17(9): 889-896.

5. Gohel MC, Parikh RK, Padshala MN, Sarvaiya KG, Jena DG. Formulation and optimization of directly compressible isoniazid is modified release matrix tablet. Indian J Pharm Sci. 2007; 69:640-5.

6. Tobyn MJ, Stani FJN, Baichwal AR, Mc Call TW. Prediction of physical properties of a novel polysaccharide-controlled release system. Int J Pharm. 1996; 128:113-22.

7. Praveen KT, Pallavi Y, Deepthi K, Narayana RP. Formulation and evaluation of Entacapone sustained release matrix tablets. The Pharma Innovation. 2014; 3(8): 80-88.

8. Lachmann L, Liebermann HA, Kanig JL. The Theory and Practice of Industrial Pharmacy, CBS publishers and distributors, New Delhi, 2007.

9. Wise DL. Handbook of Pharmaceutical Controlled Release Technology, Marcel Dekker Inc, NY, USA, 2000.

10. Abdu S, Poddar SS. A flexible technology for modified release of drugs multi layered tablets. Journal of Control Release. 2004; 97: 393-405.

11. Aboelwafa AA, Basalious EB. Optimization and In vivo pharmacokinetic study of a novel controlled release venlafaxine hydrochloride Three-Layer Tablet. AAPS Pharm Sci Tech. 2010; 11: 1026-1037.

12. Bogan RK. Treatment options for insomnia pharmacodynamics of zolpidem extended release to benefit next-day performance. Postgrad Med. 2008; 120:161-171. 
B. Ram Prasad et al. / Design and in vivo Evaluation of Controlled Release Gliclazide Trilayer Matrix Tablets.

13. Chidambaram N, Porter W, Flood K. Formulation and characterization of new layered diffusional matrices for zeroorder sustained release. J. Control. Release. 2008; 52: 149-158;

14. Choi YW, Cui JH, Lee BJ. Formulation release characteristics and bioavailability of novel monolithic hydroxyl propyl methylcellulose matrix tablet containing acetaminophen. Journal of Control Release. 2005; 108: 351-361.

15. Dalvadi H, Patel JK. Chrnopharmaceutics pulsatile drug delivery system as current trend. Asian Journal of Pharmaceutical Sciences. 2014; 5(5): 207-30.
16. Efentakis M, Peponaki C. Formulation study and evaluation of matrix and three-layer tablet sustained drug delivery systems based on Carbopol with isosorbite mononitrate. AAPS Pharm SciTech. 2008; 9: 917-23.

17. Gautama CS, Sasha L. Fixed dose drug combinations (FDCs) rational or irrational: a view point. Br J Clin Pharmacol .2008; 65: 795-796.

18. Nada HB, Syed NA, Muhammad MHA. Validated Reversed Phase HPLC Assay for the Determination of Gliclazide in Human Plasma. Saudi Journal of Medical and Pharmaceutical Sciences. 2017; 3 (10B):1128-1132.

HOW TO CITE THIS ARTICLE: Ram Prasad B, Bhikshapathi DVRN. Design and in vivo Evaluation of Controlled Release Gliclazide Trilayer Matrix Tablets in the Management of Diabetes Mellitus. Int. J. Pharm. Sci. Drug Res. 2018; 10(5): 410-417. DOI: 10.25004/IJPSDR.2018.100508 